\title{
Can Course Design in an Online MAT Program Promote Personalized Learning through E- Teaching and E-Learning Practices?
}

\author{
http://dx.doi.org/10.3991/ijac.v5i4.2200 \\ Barbara Schwartz-Bechet \\ University of Maryland University College, Adelphi, USA
}

\begin{abstract}
The current study sought to determine if the Master of Arts in Teaching (MAT) program design promoted personalized learning in the LMS platform, Webtycho. Personalized learning provides a medium to improve efficiencies in online learning. Personalized learning is not directed or paced so much by the teacher as it is by the student's own ability and capacity to acquire knowledge [1]. A qualitative case study, paired with quantitative data, will corroborate indications, through triangulation of some, or all, of the seven multiple intelligences learning styles, student e-learning practices demonstrated, and e-teaching practices employed, to determine if personalized learning occurred with current MAT students. A recommendation of ways to meet the learning needs of all current and future students in the MAT program will be provided.
\end{abstract}

Index Terms-Personalized learning, e-learning, e-teaching, teacher education.

\section{INTRODUCTION}

There are those that claim that personalized learning is implicit in an online learning environment due to the nature of the platform [2]. Yet, creating personalized learning stems more from an individual context of learning style than the type of platform used. According to a study conducted by Ref. [3], comparing online learning outcomes to on site learning outcomes, found no difference between grades students received in either format. Ref. [4], having analyzed much online instruction, demonstrated that asynchronous online courses are effective when compared to traditionally delivered courses. Yet, it is difficult to find research on the topic of course design as a variable in outcomes achieved by students; most research identifies student satisfaction as a variable associated with outcomes. One study conducted by Ref. [5] studied the effect of course design of an online course and identified variables that positively affected problem solving and collaboration skills of the students. Greater research is needed to support the need for personalized learning and how it can best be conducted in online courses to facilitate student achievement. In a program that seeks to train educators, it is necessary to determine the best practice to ensure high quality outcomes of achievement. If best practice in online instruction encompasses personalized instruction and content, the students that we train must be able to apply the same best practice whether they teach in a traditional middle or high school or in a virtual middle or virtual high school. Identifying and modeling best

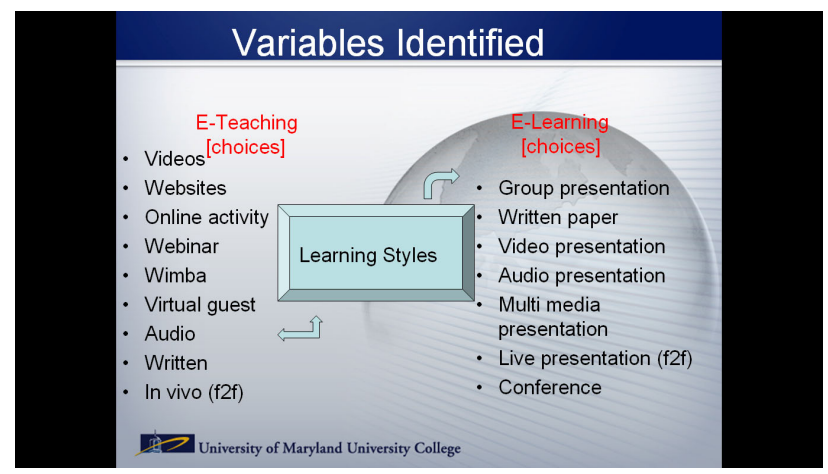

Figure 1. E-teaching and E-learning variables identified in the review of the MAT online courses

practice though course design, will enable the MAT students to be leaders in the field of education [7]. If by 2020, as Ref [8] claims, the following skills of e-teaching and e-learning practice will be utilized,

Mobile and personal Web

- Focus on individual user

- Integrated on-demand dynamic content

- Semantic web and content objects

- Widgets, mashups, metadata, dynamic web services, ontology

- User behavior

- User engagement,

practical knowledge of these skills will need to be taught now and an understanding of how individuals in both face to face and online learning situations learn best must be facilitated; it will be more important than ever to identify and utilize effective best practices of personalized instruction.

\section{METHODS}

\section{A. Rationale and overview}

The current study sought to determine if the MAT program design promoted personalized learning through personalized instruction. Personalized learning can be defined as the effort on the part of the institution to support the individual needs of any student by understanding their learning characteristics and creating an environment that is conducive to enable learning and instruction [6]. The basic elements of personalized instruction and learning include facilitation, identification of relevant learning styles or characteristics, a collegial, collaborative, and 
interactive learning environment, and use of authentic assessments. Three variables were associated with determining if personalized teaching and learning was achieved: e-teaching, e-learning practices within each MAT course, and learning styles identification. The various learning styles preferred by the students were identified, and coded, by using and applying Howard Gardner's Multiple Intelligences Theory.

\section{B. Objectives and Hypothesis}

The objective of the study was to analyze the current course design in the MAT program to develop an effective e-teaching framework in order to strengthen personalized learning. Additional objectives included the development of maximum human potential and to increase student achievement in the MAT program at UMUC. Based upon the proposed objectives, the following hypothesis was developed: 1) Students would receive better grades if the e-teaching and e- learning opportunities presented in the MAT courses are consistent with the way students perceive they learn best, 2) Provision of a variety and choice of e-teaching and e- learning opportunities would be an effective way to personalize learning (Differentiated Instruction), 3) Current MAT courses may not provide enough choice of e-teaching and e- learning opportunities.

\section{Participants}

The research population included MAT students who were taking courses in the Summer of 2011. All 70 students were sent a survey to determine their perceived learning style. Of the 70 students surveyed, $56 \%$ responded to the survey. In addition, grades of MAT students were reviewed from Spring 2011 and Summer 2011 in four of the courses offered, and that were comparable, which included a total of $100+$ students.

\section{Data Collection}

The various learning styles preferred by the students were identified, and coded, by using and applying Howard Gardner's Multiple Intelligences Theory. Through provision of two Likert type surveys placed in all MAT courses during a Summer semester; a record of student preference of learning style was created. Once preferred learning styles were identified, based upon the multiple intelligences surveys, a compilation of the students' preferred assignment deliverable styles was classified in terms of the seven Multiple Intelligences into four basic categories. For example, students who identify as creating a majority of visual deliverables, such as a website to share a video version of a lesson plan or webquests, would be identified as having visual/spatial learning styles. Learner centered strategies used in the UMUC MAT courses that reflected effective e-teaching practices were also identified and coded. Personalized learning was then measured through use of a qualitative case study, paired with quantitative data, that used triangulation (the convergence of data from multiple data collection sources) of learning styles identified through the seven multiple intelligences surveys, the e-learning practices demonstrated through identification of the assignment styles submitted, and the e-teaching practices used to facilitate learning. The purpose was to determine what types of personalized learning had been actualized. Achievement of personalized learning was identified

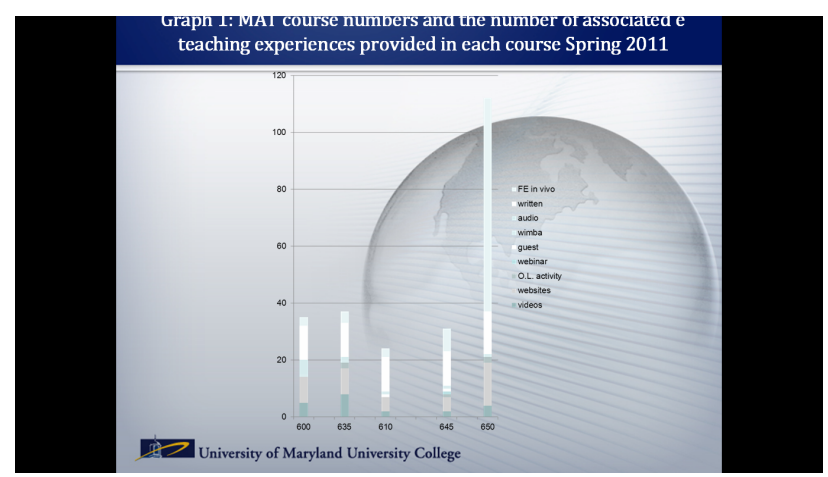

Figure 2. MAT Course Numbers and the Number of Associated eTeaching Experiences Provided in Courses, Spring2011

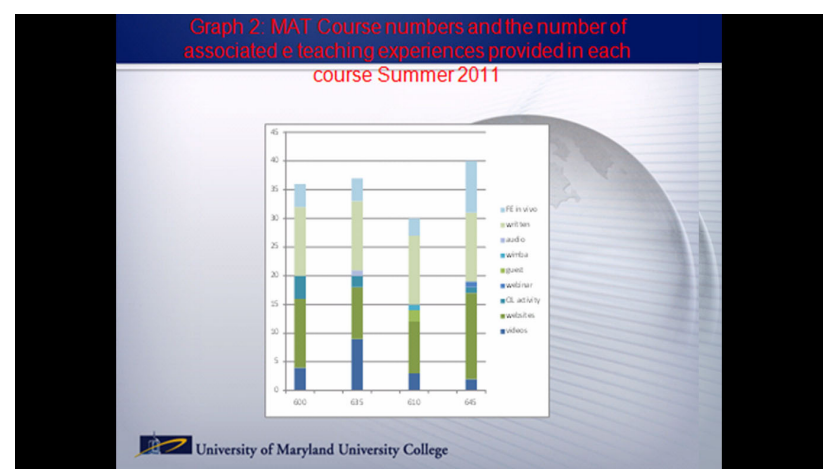

Figure 3. MAT Course Numbers and the Number of Associated eTeaching Opportunities in the Summer 2011

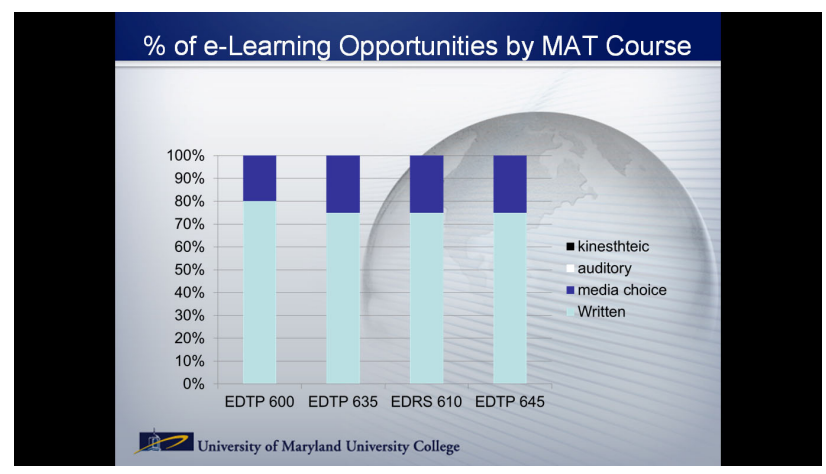

Figure 4. Percentage of e-Learning Opportunities by MAT Course

following analysis of congruence among the three variables. Based upon the results, recommendations for ways to improve personalized learning were developed.

Triangulation of data occurred following collection of the students' perceived learning styles as identified by the surveys distributed in Summer 2011. Data sources were collected through grade books and grades from Summer 2011. E-teaching variables were identified and designated by reviewing the online course teaching strategies and media employed, and e-learning variables were identified and designated by reviewing assignment choice options within each course.

\section{E. Design, Procedures, and Data Outcomes}

The design of the study was a combination of qualitative and quantitative research strategies. Data and methodological triangulation were used. Data triangulations entailed gathering data through several sampling strategies, of which survey, course content review, and grades were collected, and, between-method triangulation in- 
volved contrasting research methods which were the survey, the grade review as well as quantification of percentage of e-teaching and e-learning opportunities.

The data collected through the use of the personalized learning styles inventory resulted in the following:

TABLE I.

PERSONALIZED LEARNING STYLE INVENTORY RESULTS

\begin{tabular}{|l|c|}
\hline \multicolumn{1}{|c|}{ Learning Style } & $\%$ \\
\hline Auditory & 26 \\
\hline Visual & 32 \\
\hline Kinesthetic & 27 \\
\hline Combination & 15 \\
\hline
\end{tabular}

Auditory referred to those who indicated that they learned best by listening to new material. Visual referred to those who indicated that they learned best through visual representation of material, such as printed text. Kinesthetic referred to those who indicated that they felt that they learned best when they were more actively engaged in their learning, such as being involved in an active online discussion through Skype or a webinar or through a chat room where a project is being jointly created. Combination refers to those who indicated that they believed they learned best when they had materials presented visually and with auditory support, such as through the use of videos, etc.

The e-teaching experiences that were identified in each course during Spring and Summer 2011 were coded and counted. The identified experiences were coded as follows: video, website use, online activity, webinar, guestspeaker, web conferencing through the use of Wimba (www.wimba.com/products/wimba_classroom) , audio, written material, f2 $\mathrm{f}$ in vivo. Based upon the actual number count, there were more written e-teaching strategies used in Spring 2011 than any one other teaching strategy (with the exception of face to face in the internship course that is not offered in the summer). And in Summer 2011, written strategies were used most frequently but there was an increase in the number of websites used as well as an increase in all other identified e-teaching strategies.

The amounts of e-learning opportunities were also identified and were classified based upon the type of assignments that were required in each of the courses that were reviewed during both Spring and Summer 2011. The percentage of e-learning opportunities over all courses in both Spring and Summer 2011, resulted in an overwhelming $70 \%$ use of required written assignments with no other choice allowed. And, only $20 \%$ - $25 \%$ use of multi-media enhanced choice was allowed to enable the development of a required assignment.

The number of A grades were also compared between Spring 2011 and Summer 2011 in order to determine if there might be any evidence of a relationship between the grades and the types of assignments required. Therefore, it was hypothesized that by requiring more written assignments, there may not have resulted in many A grades for those who self-identified as anything other than a visual learner. The results of this comparison were inconclusive with the exception being that there were more A

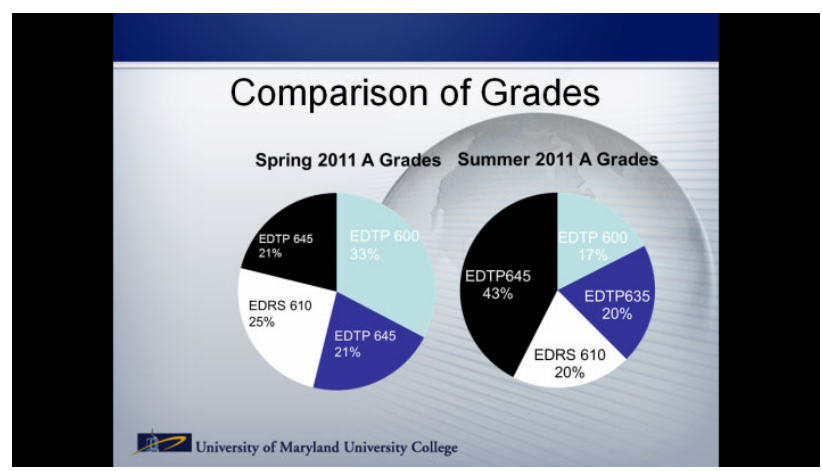

Figure 5. Comparison of Grades between Spring 2011 and Summer 2011

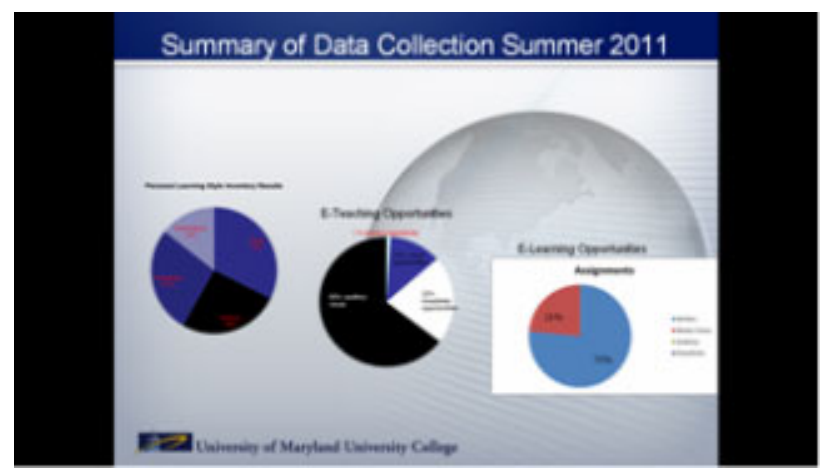

Figure 6. Summary of Data Collected Summer 2011

grades in one particular course that added more variety of e-teaching strategies rather than e-learning opportunities from Spring 2011 to Summer 2011: EDTP 645 - Subject Methods and Assessment - 21\% A grades in Spring 2011and 43\% A grades in Summer 2011.

Once the data sources were collected and analyzed individually, the triangulation began. By looking at a variety of variables, it was possible to recognize subtle changes that occurred between semesters and enabled identification of both e-learning and e-teaching strategies that were used most frequently and/or were lacking. Based upon the review of data, proposed changes can be made and implemented in a systematic way and a definition of how best to personalize learning can be created for the UMUC MAT program.

The next step was the analysis and the identification of personalized learning factors as compared to the traditional learning models. The comparison of learner as a constant to the learner as a variable [6], as well as interaction and process as key variables, were added to the overall description of the need for differentiated instruction as a practice in the UMUC MAT program.

\section{RESULTS AND DISCUSSION}

The results indicated that most students identified themselves as visual learners, yet self-identified auditory and kinesthetic learners were almost equal in number of respondents. Research has indicated that the majority of learners learn best through the use of a combination of multiple learning methods. However, if an individual perceives that they learn better through one learning style over another, that is a variable that must be considered and that learning style must be provided so as to assist in the greater self-efficacy and success of the individual student. In MAT courses that provided more variety of 
learning experiences and more choices in assignment presentations, the students did not necessarily have better grades than those in courses that used and/or expected less multi-media applications (visual/kinesthetic/combination). The data did indicate that all students in the Spring 2011 and the Summer 2011 semesters were learning, as evidenced by the large percentage of A grades (please see Fig. 5). However, there was no indication that personalized learning was affected by course design. As indicated by Ref. [6], personalization of instruction and of learning is the total effort of the instructor and his/her course design to identify individual student characteristic, even within an online environment, and their students' needs. The result should be the use of flexible instructional practices in an environment that is supportive of learning.

While no conclusive evidence was found to support the hypothesis that students would receive better grades if eteaching and e-learning opportunities were presented in a consistent manner with the ways that students perceived that they learned best, most students identified their learning styles with the way that most courses were providing the bulk of e-teaching strategies. The number of choices for e-learning opportunities was much more limited than that of e-teaching strategies used in most courses. It does then appear that it would be beneficial to develop more e-learning choice/options of for students in the UMUC MAT program. Development of e-teaching may not be as readily embraced due to time and money constraints and the need for students to understand material across a wide realm of learning media rather than being able to consistently select that which is 'easier' for the student. The initial research led to more questions that will need to be researched in the near future: Is there any need to increase the types of e-teaching and e-learning choices within courses? Would kinesthetic learning be considered ALL online learning modalities? Is it necessary to consider kinesthetic learning at all? Is it necessary to analyze the individual characteristics, attributes, aspects, and relations to learning objects and their properties in MAT or other UMUC courses to address personalized learning?

Based upon the results, a definition of personalized learning for the MAT program at UMUC would be: Personalized learning encompasses both the environment and the individual student and by preparing for a diversity of learners in any one online classroom, the learning platform should provide for all learners. The learning management platform (LMS) should be organized to provide for the e-teaching delivery to the students in the form of visual, auditory, and all other types of learning style strategies within the context of the class curriculum. Once that is embedded into the learning, the e-learning opportunities should be similarly allowed in their delivery to the instructor. And, if we are going to personalize our teaching, we must be able to gear e-teaching to the way our students learn. All of us process information differently, in how we receive directions, in how we organize our offices, and in how we present materials and should not be ignored.

An important variable that exists in the online environment is the unique relationship among the teacher/instructor and his/her students'. There must be time to allow for relationships to develop within the online platform by creating synchronous opportunities that include group and individual meetings. Modeling behaviors that demonstrate use of e-teaching and elearning practices provides for a greater chance of generalization on the part of the students in their own work. There must be respect as well as a clear understanding of outcomes and expectations, choice in presentation of materials. . When students have choices in how they can demonstrate their learning (such as webcasts, video conferences, youtube uploads, or research papers) they may show a greater sense of accountability for their deliverables. Perhaps by enabling students to take part in how grades are determined, such as by directly involving them in defining the criteria for assessment, they may be better prepared to develop more sincere and personal meaning from the work which they produce, therefore, enabling them to better generalize and maintain their learning in a variety of environments. [9]. Both the instructor and the students need to be motivated to create the learning environment and to make decisions as to how they would like to learn and share knowledge, especially in the context of today's society where more prescriptive and data driven curricula will flourish and the future of instructional development may go over the next 5-10 years.

\section{ACKNOWLEDGMENT}

I would like to acknowledge Dr. Jay Liebowitz, Orkand Chair at UMUC, for instituting and supporting the Faculty Research Graduate School Grants program at UMUC, which supported this research project.

\section{REFERENCES}

[1] Downs, S. (2004). Personalized learning. Retreived from http://www.downes.ca/future/personalized.htm

[2] Zajac, M. (2010). Using learning styles to personalize online learning. $\quad$ Retrieved May16, 2010 from: http://www.cren.pl/uploaded-files/cren-sgh_zajac_cwis

[3] Dabrowski, M., \& Zajac, M. (2006), 1000 opinii o edukacji, ementor nr 1913), 50-52.

[4] Bourne, J., \& Moore, J. (Eds.). (2002). Elements of quality in online education: Practice and direction. Needham, MA: The Sloan Consortium.

[5] Dole, S., \& Bloom, L. (2009). Online course design: A Case Study. International Journal for the Scholarship of Teaching and Learning, 3(1), 1-11.

[6] Keefe, J.W., \& Jenkins, J.M. (2000). Personalized Instruction. Eye on Education, inc. , Larchmont, NY.

[7] Schwartz-Bechet, B. (2010). E-learning for teachers: Best practices for modeling E-teaching practices for E-learners who will become teachers. The International Conference on E-learning in the Workplace Program.

[8] Amman,A..,Kiss,.., Hirsch, T.S., Matthies, H. (2008): Where, What, Why: Mr. Q on the Web, 2008 Retrieved Jul 10, 2012 from http://www.labnol.org/internet/web-3-concepts-explained/8908/

[9] National Association of Secondary School Principals, The Education Alliance. (2004). Breaking Ranks II: Strategies for Leading High School Reform Reston, VA: National Association of Secondary School Principals. Retrieved July 12, 2012 from http://www.e3smallschools.org/pl.html

\section{AUTHOR}

Barbara Schwartz-Bechet is the Director of Certification Programs and full Professor at The University of Maryland University College, Adelphi, MD 20783 USA (e-mail: bschwartz-bechet@umuc.edu).

This work was supported in part by the Faculty Research Support Grant, UMUC Graduate School. Received 30 March 2012. Published as resubmitted by the author 14 November 2012. 